\title{
Lipid emulsion-mediated reversal of toxic-dose aminoamide local anesthetic-induced vasodilation in isolated rat aorta
}

\author{
Seong-Ho Ok ${ }^{1}$, Jeong Yeol Han ${ }^{2}$, Soo Hee Lee ${ }^{2}$, Il-Woo Shin ${ }^{1}$, Heon Keun Lee ${ }^{1}$, Young-Kyun Chung ${ }^{1}$, \\ Mun-Jeoung $\mathrm{Choi}^{3}$, and Ju-Tae Sohn ${ }^{4}$ \\ Department of Anesthesiology and Pain Medicine, ${ }^{1}$ Gyeongsang National University School of Medicine, ${ }^{2}$ Gyeongsang National \\ University Hospital, ${ }^{3}$ Department of Oral and Maxillofacial Surgery, Gyeongsang National University Hospital, ${ }^{4}$ Department of \\ Anesthesiology and Pain Medicine, Institute of Health Sciences, Gyeongsang National University School of Medicine, Jinju, Korea
}

Background: Intravenous lipid emulsion has been used to treat systemic toxicity of local anesthetics. The goals of this in vitro study were to determine the ability of two lipid emulsions (Intralipid ${ }^{\circledR}$ and Lipofundin ${ }^{\circledR}$ MCT/LCT) to reverse toxic dose local anesthetic-induced vasodilation in isolated rat aortas.

Methods: Isolated endothelium-denuded aortas were suspended for isometric tension recording. Vasodilation was induced by bupivacaine $\left(3 \times 10^{-4} \mathrm{M}\right)$, ropivacaine $\left(10^{-3} \mathrm{M}\right)$, lidocaine $\left(3 \times 10^{-3} \mathrm{M}\right)$, or mepivacaine $\left(7 \times 10^{-3} \mathrm{M}\right)$ after precontraction with $60 \mathrm{mM} \mathrm{KCl}$. Intralipid ${ }^{\circledR}$ and Lipofundin ${ }^{\circledR}$ MCT/LCT were then added to generate concentrationresponse curves. We also assessed vasoconstriction induced by $60 \mathrm{mM} \mathrm{KCl}, 60 \mathrm{mM} \mathrm{KCl}$ with $3 \times 10^{-4} \mathrm{M}$ bupivacaine, and $60 \mathrm{mM} \mathrm{KCl}$ with $3 \times 10^{-4} \mathrm{M}$ bupivacaine plus 1.39\% lipid emulsion (Intralipid ${ }^{\circledR}$ or Lipofundin ${ }^{\circledR}$ MCT/LCT).

Results: The two lipid emulsions reversed vasodilation induced by bupivacaine, ropivacaine, and lidocaine but had no effect on vasodilation induced by mepivacaine. Lipofundin ${ }^{\circledR}$ MCT/LCT was more effective than Intralipid ${ }^{\circledR}$ in reversing bupivacaine-induced vasodilation. The magnitude of lipid emulsion-mediated reversal of vasodilation induced by high-dose local anesthetics was as follows (from highest to lowest): $3 \times 10^{-4} \mathrm{M}$ bupivacaine-induced vasodilation, $10^{-3} \mathrm{M}$ ropivacaine-induced vasodilation, and $3 \times 10^{-3} \mathrm{M}$ lidocaine-induced vasodilation.

Conclusions: Lipofundin ${ }^{\circledR}$ MCT/LCT-mediated reversal of bupivacaine-induced vasodilation was greater than that of Intralipid ${ }^{\circledR}$; however, the two lipid emulsions equally reversed vasodilation induced by ropivacaine and lidocaine. The magnitude of lipid emulsion-mediated reversal of vasodilation appears to be correlated with the lipid solubility of the local anesthetic. (Korean J Anesthesiol 2013; 64: 353-359)

Key Words: Aorta, Bupivacaine, Lipid emulsion, Systemic toxicity, Vasodilation.

Received: December 31, 2012. Revised: February 17, 2013. Accepted: March 1, 2013.

Corresponding author: Ju-Tae Sohn, M.D., Department of Anesthesiology and Pain Medicine, Gyeongsang National University Hospital, 90, Chilam-dong, Jinju 660-702, Korea. Tel: 82-55-750-8586, Fax: 82-55-750-8142, E-mail: jtsohn@nongae.gsnu.ac.kr

(c) This is an open-access article distributed under the terms of the Creative Commons Attribution Non-Commercial License (http:// creativecommons.org/licenses/by-nc/3.0/), which permits unrestricted non-commercial use, distribution, and reproduction in any medium, provided the original work is properly cited. 


\section{Introduction}

Intravenous lipid emulsions such as Intralipid ${ }^{\circledR}$ and Lipofundin ${ }^{\circledR}$ MCT/LCT have been used to treat local anesthetic systemic toxicity [1-8]. Toxic doses of local anesthetics that belong to the n-alkyl-substituted pipecholyl xylidine family inhibit the voltage-operated calcium channel-mediated contraction induced by low doses of local anesthetic. Thus local anesthetics have a dose-dependent vascular effect, inducing vasoconstriction at low doses and inducing vasodilation (release of vasoconstriction) at high doses [9-15]. SMOFlipid ${ }^{\circledR}$ emulsion has been shown to reverse vasodilation induced by a toxic dose of levobupivacaine in the isolated rat aorta [15]. Intralipid ${ }^{\circledR}$, which consists of $100 \%$ long-chain triglycerides, is commonly used to treat local anesthetic systemic toxicity, and Lipofundin ${ }^{\circledR}$ MCT/LCT, which consists of $50 \%$ long-chain triglycerides and $50 \%$ medium-chain triglycerides, is sometimes used to treat local anesthetic systemic toxicity [1-8]. Vaconstriction potency induced by local anesthetics is mainly determined by lipid solubility, among the physicochemical properties of local anesthetics [12]. However, studies investigating the ability of these two lipid emulsions (Lipofundin ${ }^{\circledR}$ MCT/LCT and Intralipid ${ }^{\circledR}$ ) to extract local anesthetics and promote recovery from cardiac arrest induced by a toxic dose of bupivacaine have reported inconsistent results [16-19]. Therefore, the goal of this in vitro study was to investigate the ability of Lipofundin ${ }^{\circledR}$ MCT/ LCT and Intralipid ${ }^{\circledR}$ to reverse vasodilation induced by toxic doses of local anesthetics (bupivacaine, ropivacaine, lidocaine, and mepivacaine) in the isolated rat aorta. We tested the hypothesis that the extent of lipid emulsion-mediated reversal of vasodilation induced by a toxic dose of local anesthetic may be dependent upon the kind of triglyceride (long- or mediumchain).

\section{Materials and Methods}

All experimental procedures and protocols were approved by the Institutional Animal Care and Use Committee at Gyeongsang National University.

\section{Preparation of aortic rings for tension measurement}

Preparation of aortic rings for tension measurement was performed as previously described [14]. Male Sprague-Dawley rats weighing 250-300 g were anesthetized by intramuscular injection of zoletil (15 mg/kg, Virbac Laboratories, Carros, France). The descending thoracic aorta was dissected free, and surrounding connective tissues and fat were removed under microscopic guidance in a Krebs solution bath of the following composition: $118 \mathrm{mM} \mathrm{NaCl}, 4.7 \mathrm{mM} \mathrm{KCl}, 1.2 \mathrm{mM} \mathrm{MgSO}_{4}$,
$1.2 \mathrm{mM} \mathrm{KH}_{2} \mathrm{PO}_{4}, 2.4 \mathrm{mM} \mathrm{CaCl}_{2}, 25 \mathrm{mM} \mathrm{NaHCO}$, and $11 \mathrm{mM}$ glucose. The aorta was then cut into $2.5-\mathrm{mm}$ rings, suspended on Grass isometric transducers (FT-03, Grass Instrument, Quincy, MA, USA) under a 3.0-g resting tension in a 10-ml Krebs bath at $37^{\circ} \mathrm{C}$, and aerated continuously with $95 \% \mathrm{O}_{2}$ and $5 \% \mathrm{CO}_{2}$ to maintain $\mathrm{pH}$ values within the range of 7.35-7.45. The rings were equilibrated at a $3.0-\mathrm{g}$ resting tension for $120 \mathrm{~min}$, and the bath solution was changed every $30 \mathrm{~min}$. The endothelium was removed from the aortic rings by inserting a 25 -gauge needle tip into the lumen of the rings and gently rubbing the ring for a few seconds. After contractions induced by $10^{-8} \mathrm{M}$ phenylephrine stabilized, endothelial denudation of aortic ring was confirmed by observation of less than $15 \%$ relaxation in response to acetylcholine $\left(10^{-5} \mathrm{M}\right)$. The contractile response induced by an isotonic $60 \mathrm{mM} \mathrm{KCl}$ solution was measured for all aortic rings to check vascular smooth muscle viability and was used as a reference value $(100 \%)$. The isotonic $60 \mathrm{mM} \mathrm{KCl}$ solution was prepared by replacing the $\mathrm{NaCl}$ in $\mathrm{Krebs}$ solution with an equimolar amount of $\mathrm{KCl}$. After washing out $\mathrm{KCl}$ from the organ bath and allowing the return of isometric tension to baseline, the main experiments were performed according to experimental protocols described below. Each ring was used for only one concentration-response curve induced by bupivacaine alone or a local anesthetic (bupivacaine, ropivacaine, lidocaine and mepivacaine) plus lipid emulsion. Because this in vitro study used endothelium-denuded aorta, the Krebs solution contained the nitric oxide synthase inhibitor $\mathrm{N}^{\mathrm{W}}$-nitro- $\mathrm{L}$ arginine methyl ester (L-NAME, $10^{-4} \mathrm{M}$ ) to prevent the release of endogenous nitric oxide from residual endothelium [14].

\section{Experimental protocol}

The first series of experiments was designed to determine which lipid emulsion (Intralipid ${ }^{\circledR}$ and Lipofundin ${ }^{\circledR}$ MCT/ LCT) more effectively reverses vasodilation induced by a high dose of aminoamide local anesthetic in endotheliumdenuded aorta precontracted with isotonic $\mathrm{KCl}(60 \mathrm{mM})$. We chose the local anesthetic concentrations based on the results of previous studies $\left(3 \times 10^{-4} \mathrm{M}\right.$ bupivacaine, $10^{-3} \mathrm{M}$ ropivacaine, $3 \times 10^{-3} \mathrm{M}$ lidocaine, $7 \times 10^{-3} \mathrm{M}$ mepivacaine) [1015]. After the local anesthetic produced a sustained and stable vasodilation, incremental doses of the lipid emulsion $(0.48 \%$, $0.95 \%, 1.39 \%, 1.81 \%, 2.22 \%$, and $2.60 \%$ ) were added to generate concentration-response curves. Subsequent concentration of lipid emulsion was added to the organ bath after the previous concentration of lipid emulsion produced a sustained and stable response for $5 \mathrm{~min}$.

The second series of experiment was performed to confirm that the Lipofundin ${ }^{\circledR}$ MCT/LCT-mediated reversal of vasodilation induced by $3 \times 10^{-4} \mathrm{M}$ bupivacaine was greater 
than the Intralipid ${ }^{\circledR}$-mediated reversal. We assessed contraction induced by the isotonic $60 \mathrm{mM} \mathrm{KCl}$ solution, isotonic $60 \mathrm{mM}$ $\mathrm{KCl}$ with $3 \times 10^{-4} \mathrm{M}$ bupivacaine, and isotonic $60 \mathrm{mM} \mathrm{KCl}$ with $3 \times 10^{-4} \mathrm{M}$ bupivacaine plus lipid emulsion (1.39\% Intralipid $^{\circledR}$ or $1.39 \%$ Lipofundin ${ }^{\circledR}$ MCT/LCT) in isolated endotheliumdenuded rat aorta with resting tension.

\section{Materials}

All drugs were of the highest purity commercially available. Acetylcholine, phenylephrine, and L-NAME were obtained from Sigma Aldrich (St Louis, MO, USA). Ropivacaine was donated by AstraZeneca Korea (Seoul, Korea). Mepivacaine
A

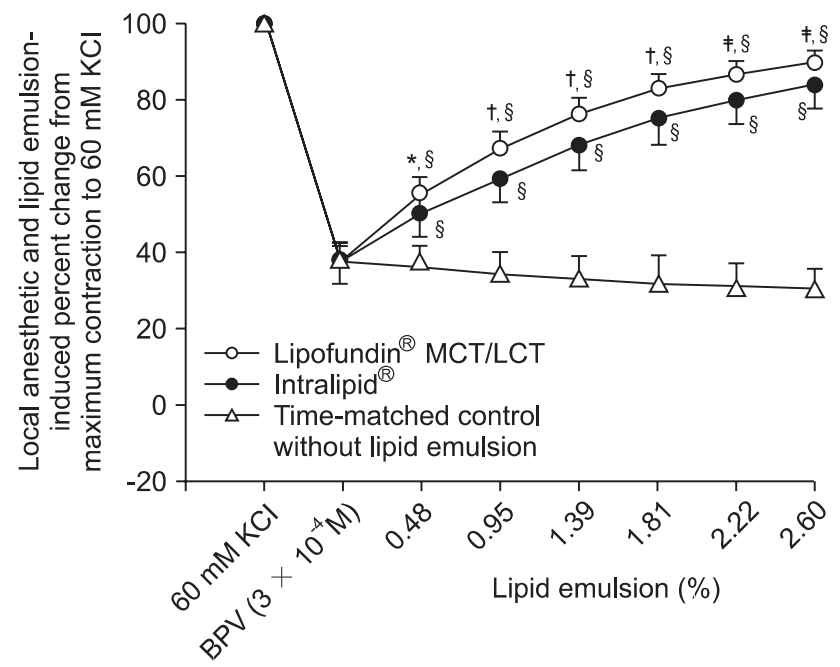

B

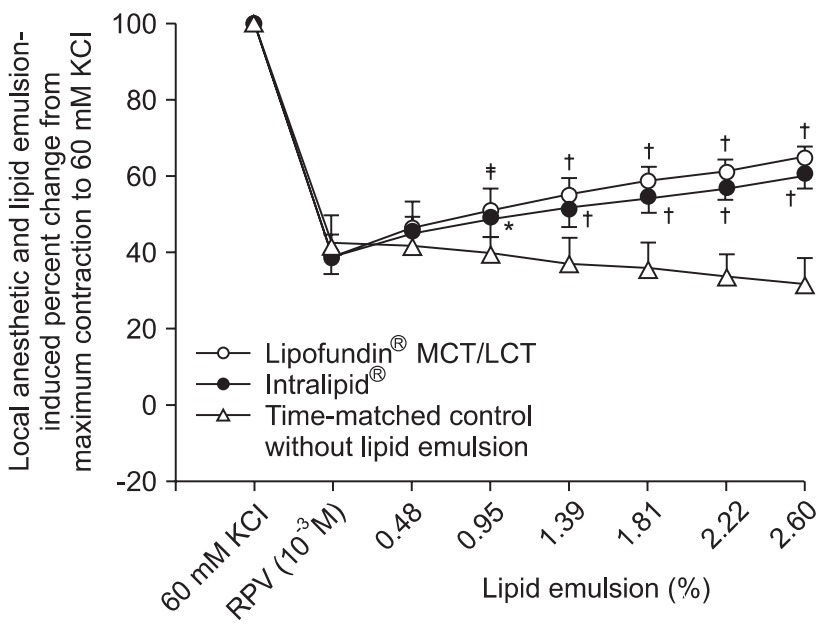

C

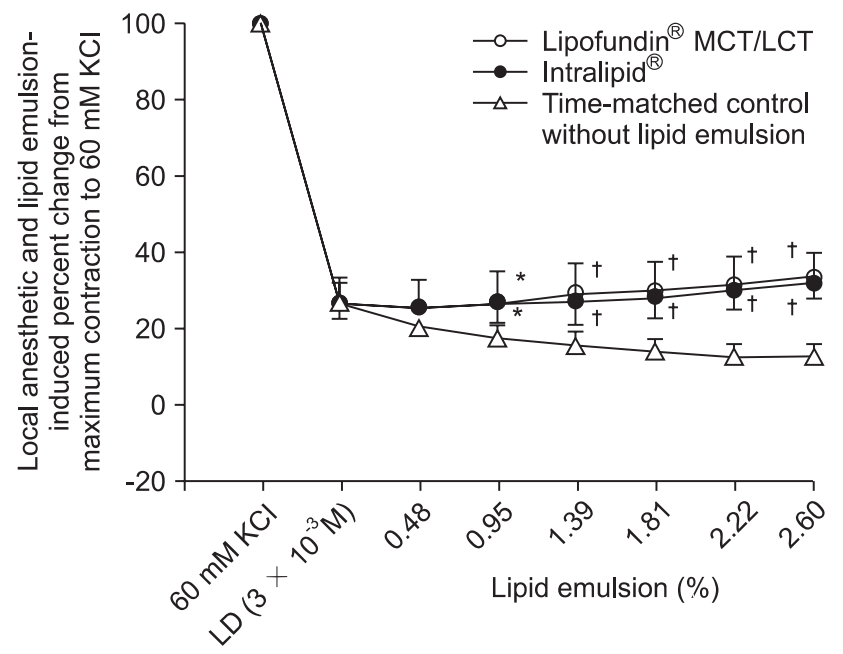

D

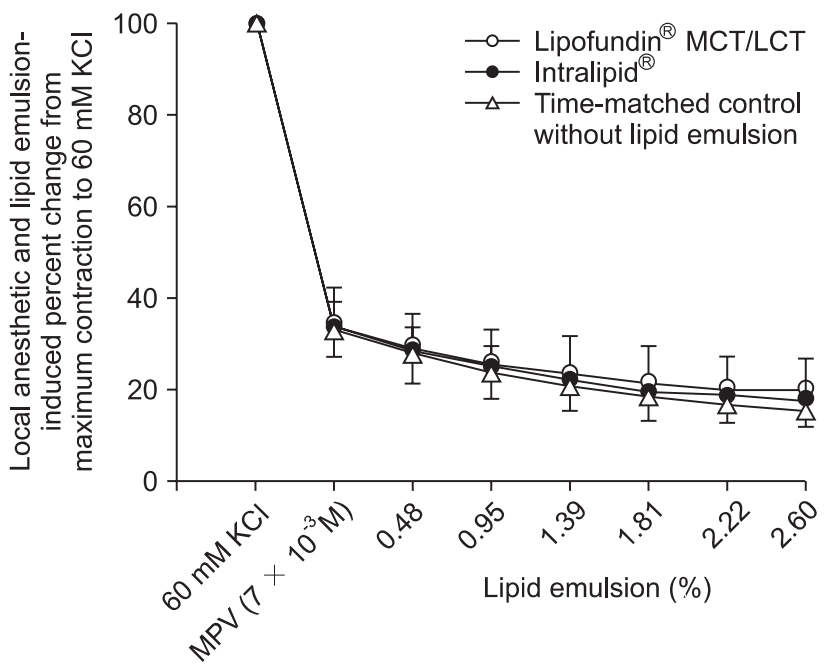

Fig. 1. Intralipid ${ }^{\circledR}$ and Lipofundin ${ }^{\circledR}$ MCT/LCT concentration-response curves in endothelium-denuded aorta precontracted with 60 mM $\mathrm{KCl}$ and treated with $3 \times 10^{-4} \mathrm{M}$ bupivacaine (BPV, A), $10^{-3} \mathrm{M}$ ropivacaine (RPV, B), $3 \times 10^{-3} \mathrm{M}$ lidocaine (LD, C), or $7 \times 10^{-3} \mathrm{M}$ mepivacaine $(\mathrm{MPV}, \mathrm{D})$. Data are shown as mean $\pm \mathrm{SD}$ and expressed as percent change from maximal precontraction value $[100 \%=2.90 \pm 0.30 \mathrm{~g}[\mathrm{n}=$ 13] for Lipofundin ${ }^{\circledR}$ MCT/LCT treatment, $100 \%=2.95 \pm 0.34 \mathrm{~g}\left[\mathrm{n}=13\right.$ ] for Intralipid ${ }^{\circledR}$ treatment, and $100 \%=2.64 \pm 0.29 \mathrm{~g}$ [n $=6$ ] for timematched control without lipid emulsion in (A); $100 \%=2.66 \pm 0.42 \mathrm{~g}[\mathrm{n}=9]$ for Lipofundin ${ }^{\circledR}$ MCT $/$ LCT treatment, $100 \%=2.58 \pm 0.28 \mathrm{~g}[\mathrm{n}=$ 9] for Intralipid ${ }^{\circledR}$ treatment, and $100 \%=2.40 \pm 0.49 \mathrm{~g}[\mathrm{n}=6]$ for time-matched control without lipid emulsion in (B); $100 \%=2.92 \pm 0.30 \mathrm{~g}$ [n = 9] for Lipofundin ${ }^{\circledR}$ MCT/LCT treatment, $100 \%=2.72 \pm 0.40 \mathrm{~g}\left[\mathrm{n}=9\right.$ ] for Intralipid ${ }^{\circledR}$ treatment, and $100 \%=2.67 \pm 0.38 \mathrm{~g}[\mathrm{n}=6]$ for timematched control without lipid emulsion in (C); $100 \%=2.56 \pm 0.27 \mathrm{~g}[\mathrm{n}=8]$ for Lipofundin ${ }^{\circledR}$ MCT $/ \mathrm{LCT}$ treatment, $100 \%=2.52 \pm 0.30 \mathrm{~g}[\mathrm{n}=$ 8] for Intralipid ${ }^{\circledR}$ treatment, and $100 \%=2.58 \pm 0.29 \mathrm{~g}[\mathrm{n}=8]$ for time-matched control without lipid emulsion in (D)]. N indicates number of descending thoracic aortic rings. (A) $* \mathrm{P}<0.05,{ }^{\dagger} \mathrm{P}<0.001,{ }^{\dagger} \mathrm{P}<0.01$ versus Intralipid ${ }^{\circledR},{ }^{\S} \mathrm{P}<0.001$ versus time-matched control. (B, C) $* \mathrm{P}<0.05$, ${ }^{\dagger} \mathrm{P}<0.001,{ }^{\dagger} \mathrm{P}<0.01$ versus time-matched control. 
was donated by Hana Pharmaceutical Co., Ltd. (Gyeonggido, Korea). Bupivacaine and lidocaine were purchased from Reyon Pharmaceutical Co., Ltd. (Seoul, Korea) and Daihan Pharmaceutical Co., Ltd. (Seoul, Korea), respectively. Intralipid ${ }^{\circledR}$ $20 \%$ and Lipofundin ${ }^{\circledR}$ MCT/LCT $20 \%$ were donated by Fresenius Kabi Korea (Seoul, Korea) and B. Braun Korea (Seoul, Korea), respectively.

\section{Data analysis}

Values are expressed as mean \pm standard deviation (SD). Vascular responses induced by local anesthetics and lipid emulsion in endothelium-denuded aorta precontracted with 60 $\mathrm{mM} \mathrm{KCl}$ are expressed as percent of baseline (precontraction value). Vascular responses induced by isotonic $60 \mathrm{mM} \mathrm{KCl}$, isotonic $60 \mathrm{mM} \mathrm{KCl}$ with $3 \times 10^{-4} \mathrm{M}$ bupivacaine, and isotonic 60 $\mathrm{mM} \mathrm{KCl}$ with $3 \times 10^{-4} \mathrm{M}$ bupivacaine plus lipid emulsion (1.39\% Intralipid $^{\circledR}$ or $1.39 \%$ Lipofundin ${ }^{\circledR}$ MCT/LCT) are expressed as the percentage of the maximal contraction induced by isotonic $60 \mathrm{mM} \mathrm{KCl}$. The magnitude of lipid emulsion-mediated reversal is expressed as the percentage of reversal of the local anestheticinduced vasodilation (absolute value). The effects of each lipid emulsion on vasodilation were compared by two-way analysis of variance followed by a Bonferroni post-test using GraphPad Prism version 5.00 for Windows (GraphPad Software, San Diego, CA, USA). The magnitude of vasoconstriction induced by 60 $\mathrm{mM} \mathrm{KCl}$ alone, $60 \mathrm{mM} \mathrm{KCl}$ plus $3 \times 10^{-4} \mathrm{M}$ bupivacaine, and 60 $\mathrm{mM} \mathrm{KCl}$ with both bupivacaine $\left(3 \times 10^{-4} \mathrm{M}\right)$ and lipid emulsion (1.39\%) was compared by one-way analysis of variance followed by a Bonferroni post-test. $\mathrm{N}$ indicates the number of descending rat thoracic aortic rings. $P$ values less than 0.05 were considered significant.

\section{Results}

After precontraction of endothelium-denuded aorta with isotonic $60 \mathrm{mM} \mathrm{KCl}$, both lipid emulsions reversed vasodilation induced by $3 \times 10^{-4} \mathrm{M}$ bupivacaine $(\mathrm{P}<0.001$ versus timematched control without lipid emulsion at $0.48-2.60 \%$ lipid emulsion; Fig. 1A). The Lipofundin ${ }^{\circledR}$ MCT/LCT concentrationresponse curves were higher than Intralipid ${ }^{\circledR}$ concentrationresponse curves $(\mathrm{P}<0.05$ at $0.48-2.60 \%$ lipid emulsion; Fig. 1A). In addition, both lipid emulsions reversed vasodilation induced by $10^{-3} \mathrm{M}$ ropivacaine and $3 \times 10^{-3} \mathrm{M}$ lidocaine $(\mathrm{P}<0.05$ versus time-matched control without lipid emulsion at $0.95-$ $2.60 \%$ lipid emulsion; Fig. 1B and 1C); however, Lipofundin ${ }^{\circledR}$ MCT/LCT concentration-response curves did not differ significantly from Intralipid ${ }^{\circledR}$ concentration-response curves (Fig. 1B and 1C). Neither Lipofundin ${ }^{\circledR}$ MCT/LCT nor Intralipid ${ }^{\circledR}$ reversed vasodilation induced by $7 \times 10^{-3} \mathrm{M}$ mepivacaine (Fig.
1D).

Vasoconstriction induced by $60 \mathrm{mM} \mathrm{KCl}$ with $3 \times 10^{-4} \mathrm{M}$ bupivacaine was lower than that induced by $60 \mathrm{mM} \mathrm{KCl}$ alone ( $\mathrm{P}<0.001$; Fig. 2). However, vasoconstriction induced by 60 $\mathrm{mM} \mathrm{KCl}$ with $3 \times 10^{-4} \mathrm{M}$ bupivacaine plus $1.39 \%$ lipid emulsion (Lipofundin ${ }^{\circledR}$ MCT/LCT or Intralipid ${ }^{\circledR}$ ) was higher than that induced by $60 \mathrm{mM} \mathrm{KCl}$ with $3 \times 10^{-4} \mathrm{M}$ bupivacaine $(\mathrm{P}<0.001$; Fig. 2). Furthermore, vasoconstriction induced by $60 \mathrm{mM} \mathrm{KCl}$ with $3 \times 10^{-4} \mathrm{M}$ bupivacaine plus $1.39 \%$ Lipofundin ${ }^{\circledR} \mathrm{MCT} / \mathrm{LCT}$ was higher than that induced by $60 \mathrm{mM} \mathrm{KCl}$ with $3 \times 10^{-4} \mathrm{M}$ bupivacaine plus $1.39 \%$ Intralipid ${ }^{\circledR}(\mathrm{P}<0.05$; Fig. 2$)$

Using the absolute value of local anesthetic-induced vasodilation as the reference value, the magnitude of lipid emulsion-mediated reversal of vasodilation was as follows (from highest to lowest): $3 \times 10^{-4} \mathrm{M}$ bupivacaine-induced vasodilation, $10^{-3} \mathrm{M}$ ropivacaine-induced vasodilation, and $3 \times$ $10^{-3} \mathrm{M}$ lidocaine-induced vasodilation (Fig. 3).

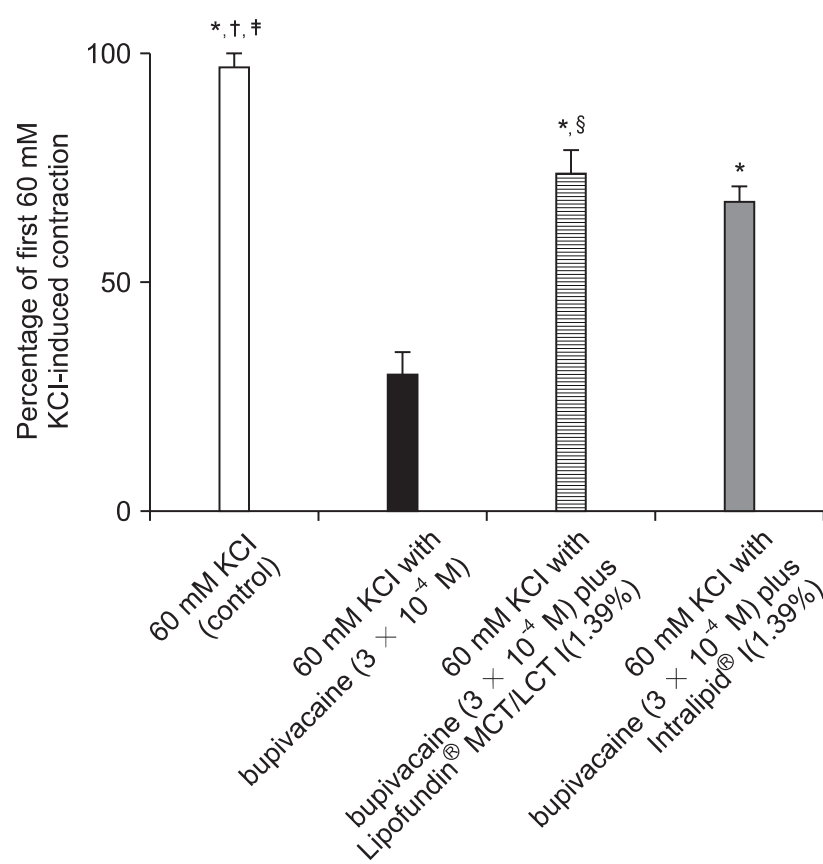

Fig. 2. Effect of $3 \times 10^{-4} \mathrm{M}$ bupivacaine with or without $1.39 \%$ lipid emulsion (Lipofundin ${ }^{\circledR}$ MCT/LCT or Intralipid ${ }^{\circledR}$ ) on the $60 \mathrm{mM} \mathrm{KCl-}$ induced contraction. Data are shown as mean \pm SD and expressed as percent of maximal precontraction $(100 \%=2.86 \pm 0.50 \mathrm{~g}[\mathrm{n}=8]$ for $60 \mathrm{mM} \mathrm{KCl}, 100 \%=3.19 \pm 0.36 \mathrm{~g}[\mathrm{n}=8]$ for $60 \mathrm{mM} \mathrm{KCl}$ with $3 \times 10^{-4}$ M bupivacaine, $100 \%=2.85 \pm 0.48 \mathrm{~g}[\mathrm{n}=8]$ for $60 \mathrm{mM} \mathrm{KCl}$ with $3 \times$ $10^{-4} \mathrm{M}$ bupivacaine plus $1.39 \%$ Lipofundin ${ }^{\circledR}$ MCT/LCT, and $100 \%=$ $3.00 \pm 0.46 \mathrm{~g}[\mathrm{n}=8]$ for $60 \mathrm{mM} \mathrm{KCl}$ with $3 \times 10^{-4} \mathrm{M}$ bupivacaine plus $1.39 \%$ Intralipid $^{\circledR}$ ). $\mathrm{N}$ indicates number of descending thoracic aortic rings. $* \mathrm{P}<0.001$ versus $60 \mathrm{mM} \mathrm{KCl}$ with $3 \times 10^{-4} \mathrm{M}$ bupivacaine, ${ }^{\dagger} \mathrm{P}<0.001$ versus $60 \mathrm{mM} \mathrm{KCl}$ with $3 \times 10^{-4} \mathrm{M}$ bupivacaine plus $1.39 \%$ Lipofundin ${ }^{\circledR}$ MCT/LCT, ${ }^{\dagger} \mathrm{P}<0.001$ versus $60 \mathrm{mM} \mathrm{KCl}$ with $3 \times 10^{-4} \mathrm{M}$ bupivacaine plus $1.39 \%$ Intralipid ${ }^{\circledR},{ }^{\S} \mathrm{P}<0.05$ versus $60 \mathrm{mM} \mathrm{KCl}$ with $3 \times 10^{-4} \mathrm{M}$ bupivacaine plus $1.39 \%$ Intralipid $^{\circledR}$. 
A

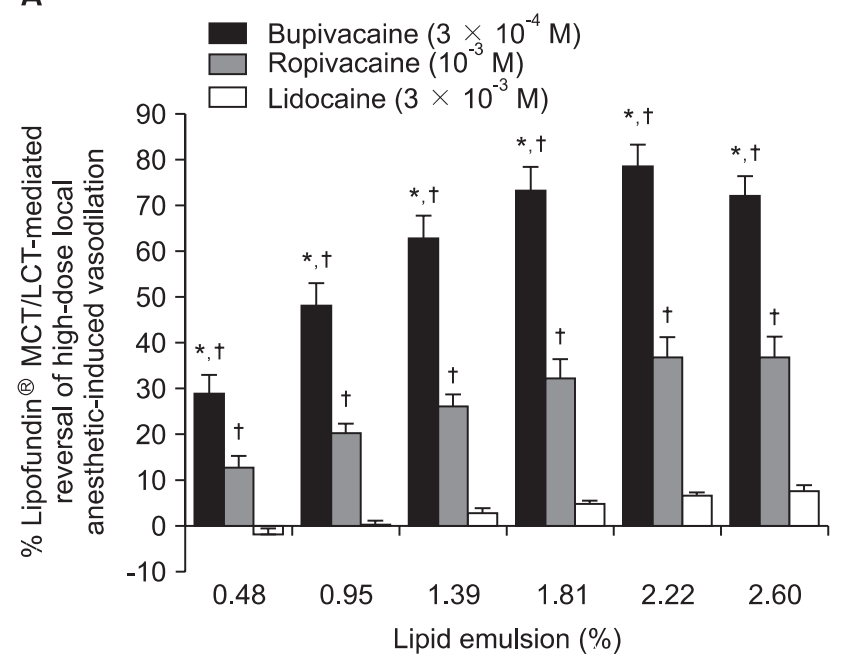

B

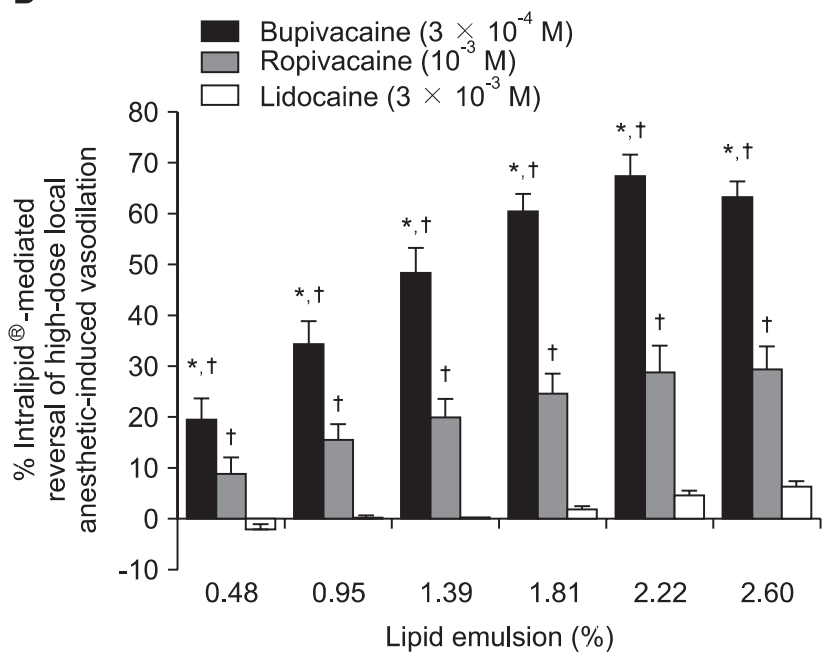

Fig. 3. Reversal of vasodilation induced by high-dose local anesthetic $\left(3 \times 10^{-4} \mathrm{M}\right.$ bupivacaine, $10^{-3} \mathrm{M}$ ropivacaine, or $3 \times 10^{-3} \mathrm{M}$ lidocaine $)$ in isolated endothelium-denuded aorta precontracted with $60 \mathrm{mM} \mathrm{KCl}$ mediated by Lipofundin ${ }^{\circledR}$ MCT/LCT (A) or Intralipid ${ }^{\circledR}$ (B). Data are shown as mean \pm SD and expressed as the percentage of reversal of absolute value of vasodilation induced by the local anesthetic $(100 \%=1.81 \pm 0.20 \mathrm{~g}$ $[\mathrm{n}=13]$ for $3 \times 10^{-4} \mathrm{M}$ bupivacaine, $100 \%=1.64 \pm 0.37 \mathrm{~g}[\mathrm{n}=9]$ for $10^{-3} \mathrm{M}$ ropivacaine, and $100 \%=2.13 \pm 0.20 \mathrm{~g}[\mathrm{n}=9]$ for $3 \times 10^{-3} \mathrm{M}$ lidocaine in A; $100 \%=1.83 \pm 0.19 \mathrm{~g}[\mathrm{n}=13]$ for $3 \times 10^{-4} \mathrm{M}$ bupivacaine, $100 \%=1.56 \pm 0.24 \mathrm{~g}[\mathrm{n}=9]$ for $10^{-3} \mathrm{M}$ ropivacaine, and $100 \%=1.98 \pm 0.28 \mathrm{~g}[\mathrm{n}=9]$ for $3 \times 10^{-3} \mathrm{M}$ lidocaine in $\left.\mathrm{B}\right) .{ }^{*} \mathrm{P}<0.001$ versus $10^{-3} \mathrm{M}$ ropivacaine, ${ }^{\dagger} \mathrm{P}<0.001$ versus $3 \times 10^{-3} \mathrm{M}$ lidocaine.

\section{Discussion}

This study is the first to demonstrate that the magnitude of Lipofundin ${ }^{\circledR}$ MCT/LCT-mediated reversal of high-dose bupivacaine-induced vasodilation may be greater than Intralipid ${ }^{\circledR}$-mediated reversal. The major findings of this in vitro study were as follows: 1) Lipofundin ${ }^{\circledR}$ MCT/LCT-mediated reversal of vasodilation induced by high-dose bupivacaine was greater than Intralipid ${ }^{\circledR}$-mediated reversal; 2) the two lipid emulsions reversed vasodilation induced by highdose aminoamide local anesthetics, including bupivacaine, ropivacaine, and lidocaine, but had no effect on vasodilation induced by high-dose mepivacaine; and 3) vasoconstriction induced by $60 \mathrm{mM} \mathrm{KCl}$ with $3 \times 10^{-4} \mathrm{M}$ bupivacaine plus $1.39 \%$ Lipofundin ${ }^{\circledR} \mathrm{MCT} / \mathrm{LCT}$ was higher than that induced by $60 \mathrm{mM}$ KCl with $3 \times 10^{-4} \mathrm{M}$ bupivacaine plus $1.39 \%$ Intralipid $^{\circledR}$.

Vasoconstriction induced by low doses of levobupivacaine, bupivacaine, ropivacaine, and mepivacaine involves the activation of voltage-operated calcium channels $[10,11,13,14,20,21]$. However, high doses of levobupivacaine $\left(3 \times 10^{-4} \mathrm{M}\right)$, ropivacaine $\left(10^{-3} \mathrm{M}\right)$, and mepivacaine $\left(10^{-2} \mathrm{M}\right)$ attenuate vasoconstriction induced by voltage-operated calcium channel activation [13-15]. Based on the results of previous studies, it can be assumed that high doses of local anesthetics inhibit voltage-operated calcium channels in vascular smooth muscle after their initial activation $[10,11,13-15,20,21]$. A previous study reported that SMOFlipid ${ }^{\circledR}$ emulsion reverses vasodilation induced by high-dose levobupivacaine and ropivacaine in aortas precontracted with $60 \mathrm{mM} \mathrm{KCl}$, which is consistent with our finding that Lipofundin ${ }^{\circledR}$ MCT/LCT and Intralipid ${ }^{\circledR}$ reversed vasodilation induced by bupivacaine, ropivacaine, and lidocaine but not mepivacaine [15]. In addition, vasoconstriction induced by $60 \mathrm{mM} \mathrm{KCl}$ with $3 \times$ $10^{-4} \mathrm{M}$ bupivacaine plus $1.39 \%$ lipid emulsion (Intralipid ${ }^{\circledR}$ and Lipofundin ${ }^{\circledR} \mathrm{MCT} / \mathrm{LCT}$ ) was greater than that induced by $60 \mathrm{mM} \mathrm{KCl}$ with $3 \times 10^{-4} \mathrm{M}$ bupivacaine alone (Fig. 2). The magnitude of lipid emulsion-mediated reversal of vasodilation induced by high-dose anesthetic (Fig. 3) was as follows: bupivacaine $\left(3 \times 10^{-4} \mathrm{M}\right)>$ ropivacaine $\left(10^{-3} \mathrm{M}\right)>$ lidocaine $\left(3 \times 10^{-3} \mathrm{M}\right)$. The n-octanol/buffer partition coefficients were 346 (bupivacaine), 115 (ropivacaine), 43 (lidocaine), and 21 (mepivacaine) [22]. Together with the findings of previous reports, our study shows that the magnitude of lipid emulsionmediated reversal correlates with the lipid solubility of the local anesthetic $[12,22]$. One of underlying mechanisms of lipid emulsion-induced reversal of local anesthetic systemic toxicity is the "lipid sink" theory, which postulates that the lipid emulsion extracts local anesthetics from tissues into the lipid phase [23]. The lipid solubility (n-octanol/buffer partition coefficient) of bupivacaine (346) is about three times higher than that of ropivacaine (115). The magnitude of lipid emulsionmediated reversal was greater for bupivacaine-induced vasodilation than ropivacaine-induced vasodilation, which may reflect the different lipid solubilities of these anesthetics [22,23]. Lipid emulsion also appears to clear bupivacaine better than ropivacaine at toxic doses that inhibit voltage-operated calcium 
channel activation in rat aortic smooth muscle. Consistent with a previous report that lipid emulsion does not improve recovery from mepivacaine-induced cardiac arrest, our results suggest that the effect of lipid emulsion on high-dose mepivacaineinduced vasodilation may be negligible or very weak compared with high-dose bupivacaine-induced vasodilation [24]. Voltageoperated calcium channel activation is another suggested mechanism (besides the lipid sink theory) to explain the effect of lipid emulsion treatment [23]. Lipid activates voltageoperated calcium channels in cardiac myocytes, suggesting that further research is needed to better understand the effect of lipid emulsion on contraction induced by voltage-operated calcium channels of vascular smooth muscle $[23,25]$.

The magnitude of lipid emulsion-mediated reversal of vasodilation induced by ropivacaine and lidocaine did not differ significantly between Lipofundin ${ }^{\circledR}$ MCT/LCT and Intralipid $^{\circledR}$ (Fig. 1B and 1C). However, Lipofundin ${ }^{\circledR}$ MCT/LCTmediated reversal of bupivacaine-induced vasodilation was greater than Intralipid ${ }^{\circledR}$-mediated reversal (Fig. 1A), suggesting better vascular tone recovery with Lipofundin ${ }^{\circledR}$ MCT/LCT treatment. SMOFlipid ${ }^{\circledR}$ emulsion (20\%) consists of $6 \%$ soybean oil, $6 \%$ medium-chain triglycerides, $5 \%$ olive oil, and $3 \%$ fish oil [26]. Intralipid ${ }^{\circledR} 20 \%$ consists of $100 \%$ long-chain triglycerides, and Lipofundin ${ }^{\circledR}$ MCT/LCT $20 \%$ consists of $50 \%$ mediumchain triglycerides and $50 \%$ long-chain triglycerides. Both Intralipid ${ }^{\circledR}$ and Lipofundin ${ }^{\circledR}$ MCT/LCT have been used to treat local anesthetic systemic toxicity [1-8]. In terms of the ability to extract local anesthetics in vitro, Intralipid ${ }^{\circledR}$ extracts 2.5 times more bupivacaine from buffer solution than lipid emulsion with $50 \%$ medium-chain triglycerides plus $50 \%$ longchain triglycerides, but Lipofundin ${ }^{\circledR}$ MCT/LCT extracts more bupivacaine from human serum than Intralipid ${ }^{\circledR}[16,17]$. In terms of lipid emulsion-mediated recovery from bupivacaineinduced cardiac arrest in vivo, Intralipid ${ }^{\circledR}$ treatment results in fewer recurrences of asystole after resuscitation than treatment with lipid emulsion containing 50\% long-chain triglycerides and 50\% medium-chain triglycerides [18]. In contrast, both lipid emulsions are equally effective at reversing the prolongation of QRS duration, atrial-His interval, and P-Q interval induced by a toxic dose of bupivacaine [19]. Lipofundin ${ }^{\circledR}$ MCT/LCT and Intralipid ${ }^{\circledR}$ did not differ significantly with regards to the magnitude of lipid emulsion-mediated reversal in vasodilation induced by high doses of ropivacaine and lidocaine (Fig. 1B and C); however, $1.39 \%$ Lipofundin ${ }^{\circledR}$ MCT/LCT was more effective than $1.39 \%$ Intralipid ${ }^{\circledR}$ at reversing bupivacaine-induced attenuation of $\mathrm{KCl}$-induced contraction (Fig. 2). These different effects may be due to differences in lipid solubility, chemical structure, stereoselectivity, and molecular weight of the local anesthetics. Discrepancies between our results and those of previous studies may be ascribed to differences in methods (isometric tension measurement versus shake-flask method), specimens (aortic rings versus heart), and conditions (in vitro versus in vivo) $[16,18]$. In addition, nanoemulsion (118.4 nm) removes bupivacaine in the phosphate-buffered saline to a greater extent than macroemulsion (432 nm), supporting our results that due to a smaller particle size, Lipofundin ${ }^{\circledR}$ MCT/LCT (280 nm) may reverse more bupivacaine-induced vasodilation than Intralipid $^{\circledR}(430 \mathrm{~nm})[18,27]$.

Extrapolation of results from this in vitro study to clinical situations should be made cautiously, because we used aortas as conduit vessels, whereas small resistance arterioles control organ blood flow in vivo. In addition, vasoconstriction induced by local anesthetics such as levobupivacaine, ropivacaine, and mepivacaine involves endothelial nitric oxide release [13-15,28]. The results obtained with endothelium-denuded aorta used in this in vitro experiment may therefore be slightly modified by endothelial nitric oxide release in vivo. Even with these limitations, our study shows that Lipofundin ${ }^{\circledR}$ MCT/LCT may provide better vascular tone recovery than Intralipid ${ }^{\circledR}$ after vasodilation induced by a toxic dose of bupivacaine. In addition, Lipofundin ${ }^{\circledR}$ MCT/LCT and Intralipid ${ }^{\circledR}$ may be equally effective as treatment for vasodilation induced by toxic doses of ropivacaine and lidocaine, because the concentrations used in this in vitro study (bupivacaine: $3 \times 10^{-4} \mathrm{M}$; ropivacaine: $10^{-3} \mathrm{M}$; lidocaine: $3 \times 10^{-3} \mathrm{M}$ ) exceed the plasma concentrations that produce the myocardial depression regarded as a sign of local anesthetic systemic toxicity (bupivacaine: $6.4 \times 10^{-6}$ to $1.85 \times 10^{-5} \mathrm{M}$; ropivacaine: $10^{-5}$ to $2.6 \times 10^{-5} \mathrm{M}$; lidocaine: $3.07 \times$ $10^{-5}$ to $\left.1.11 \times 10^{-4} \mathrm{M}\right)$ [29]. Some lipid emulsion concentrations $(0.48 \%$ and $0.95 \%)$ that reversed bupivacaine-induced vasodilation in this study are similar to the average plasma concentration (final triglyceride concentration: 1\%) reached after intravenous injection of Intralipid ${ }^{\circledR} 20 \%$ for treatment of cardiac arrest induced by a toxic dose of bupivacaine [30]. However, further study is needed to determine the appropriate dosing regimen of lipid emulsion for local anesthetic systemic toxicity.

In conclusion, Lipofundin ${ }^{\circledR}$ MCT/LCT-mediated reversal of bupivacaine-induced vasodilation was greater than Intralipid ${ }^{\circledR}$ -mediated reversal, whereas the two lipid emulsions equally reversed vasodilation induced by toxic doses of ropivacaine and lidocaine. The magnitude of lipid emulsion-mediated reversal appears to be correlated with the lipid solubility of the local anesthetic.

\section{Acknowledgments}

This research was supported by the Basic Science Research Program through the National Research Foundation of Korea (NRF) funded by the Ministry of Education, Science, and 
Technology (KRF-2011-0006783). The work was supported by National Research Foundation of Korea Grant funded by the Korea Government (2009-0072066).

\section{References}

1. Cordell CL, Schubkegel T, Light TR, Ahmad F. Lipid infusion rescue for bupivacaine-induced cardiac arrest after axillary block. J Hand Surg Am 2010; 35: 144-6.

2. Markowitz S, Neal JM. Immediate lipid emulsion therapy in the successful treatment of bupivacaine systemic toxicity. Reg Anesth Pain Med 2009; 34: 276.

3. McCutchen T, Gerancher JC. Early intralipid therapy may have prevented bupivacaine-associated cardiac arrest. Reg Anesth Pain Med 2008; 33: 178-80.

4. Zimmer C, Piepenbrink K, Riest G, Peters J. Cardiotoxic and neurotoxic effects after accidental intravascular bupivacaine administration. Therapy with lidocaine propofol and lipid emulsion. Anaesthesist 2007; 56: 449-53.

5. Dix SK, Rosner GF, Nayar M, Harris JJ, Guglin ME, Winterfield JR, et al. Intractable cardiac arrest due to lidocaine toxicity successfully resuscitated with lipid emulsion. Crit Care Med 2011; 39: 872-4.

6. Charbonneau H, Marcou TA, Mazoit JX, Zetlaoui PJ, Benhamou D. Early use of lipid emulsion to treat incipient mepivacaine intoxication. Reg Anesth Pain Med 2009; 34: 277-8.

7. Gnaho A, Eyrieux S, Gentili M. Cardiac arrest during an ultrasoundguided sciatic nerve block combined with nerve stimulation. Reg Anesth Pain Med 2009; 34: 278.

8. Litz RJ, Popp M, Stehr SN, Koch T. Successful resuscitation of a patient with ropivacaine-induced asystole after axillary plexus block using lipid infusion. Anaesthesia 2006; 61: 800-1.

9. Casati A, Putzu M. Bupivacaine, levobupivacaine and ropivacaine: are they clinically different? Best Pract Res Clin Anaesthesiol 2005; 19: 247-68.

10. Sung HJ, Sohn JT, Park JY, Hwang EM, Baik JS, Ogawa K. Direct effect of ropivacaine involves lipoxygenase pathway activation in rat aortic smooth muscle. Can J Anaesth 2009; 56: 298-306.

11. Choi YS, Jeong YS, Ok SH, Shin IW, Lee SH, Park JY, et al. The direct effect of levobupivacaine in isolated rat aorta involves lipoxygenase pathway activation and endothelial nitric oxide release. Anesth Analg 2010; 110: 341-9.

12. Sung HJ, Ok SH, Sohn JY, Son YH, Kim JK, Lee SH, et al. Vasoconstriction potency induced by aminoamide local anesthetics correlates with lipid solubility. J Biomed Biotechnol. 2012 June [2012 June 17]. Available from http://www.ncbi.nlm.nih.gov/ pubmed/22778542.

13. Sung HJ, Choi MJ, Ok SH, Lee SH, Hwang IJ, Kim HS, et al. Mepivacaine-induced contraction is attenuated by endothelial nitric oxide release in isolated rat aorta. Can J Physiol Pharmacol 2012; 90: 863-72.

14. Baik JS, Sohn JT, Ok SH, Kim JG, Sung HJ, Park SS, et al. Levobupivacaine-induced contraction of isolated rat aorta is calcium dependent. Can J Physiol Pharmacol 2011; 89: 467-76.

15. Ok SH, Sohn JT, Baik JS, Kim JG, Park SS, Sung HJ, et al. Lipid emulsion reverses levobupivacaine-induced responses in isolated rat aortic vessels. Anesthesiology 2011; 114: 293-301.

16. Mazoit JX, Le Guen R, Beloeil H, Benhamou D. Binding of longlasting local anesthetics to lipid emulsions. Anesthesiology 2009; 110: $380-6$.

17. Ruan W, French D, Wong A, Drasner K, Wu AH. A mixed (long- and medium-chain) triglyceride lipid emulsion extracts local anesthetic from human serum in vitro more effectively than a long-chain emulsion. Anesthesiology 2012; 116: 334-9.

18. Li Z, Xia Y, Dong X, Chen H, Xia F, Wang X, et al. Lipid resuscitation of bupivacaine toxicity: long-chain triglyceride emulsion provides benefits over long- and medium-chain triglyceride emulsion. Anesthesiology 2011; 115: 1219-28.

19. Candela D, Louart G, Bousquet PJ, Muller L, Nguyen M, Boyer JC, et al. Reversal of bupivacaine-induced cardiac electrophysiologic changes by two lipid emulsions in anesthetized and mechanically ventilated piglets. Anesth Analg 2010; 110: 1473-9.

20. Norén H, Lindblom B, Källfelt B. Effects of bupivacaine and calcium antagonists on the rat uterine artery. Acta Anaesthesiol Scand 1991; 35: 77-80.

21. Tokinaga Y, Ogawa K, Yu J, Kuriyama T, Minonishi T, Hatano Y. Mechanism of the ropivacaine-induced increase in intracellular $\mathrm{Ca}^{2+}$ concentration in rat aortic smooth muscle. Acta Anaesthesiol Scand 2007; 51: 1155-60.

22. Felice K, Schumann H. Intravenous lipid emulsion for local anesthetic toxicity: a review of the literature. J Med Toxicol 2008; 4: 184-91.

23. Weinberg GL. Lipid emulsion infusion: resuscitation for local anesthetic and other drug overdose. Anesthesiology 2012; 117: 180-7.

24. Zausig YA, Zink W, Keil M, Sinner B, Barwing J, Wiese CH, et al. Lipid emulsion improves recovery from bupivacaine-induced cardiac arrest, but not from ropivacaine- or mepivacaine-induced cardiac arrest. Anesth Analg 2009; 109: 1323-6.

25. Huang JM, Xian H, Bacaner M. Long-chain fatty acids activate calcium channels in ventricular myocytes. Proc Natl Acad Sci U S A 1992; 89: 6452-6.

26. Mertes N, Grimm H, Fürst P, Stehle P. Safety and efficacy of a new parenteral lipid emulsion (SMOFlipid) in surgical patients: a randomized, double-blind, multicenter study. Ann Nutr Metab 2006; 50: 253-9.

27. Morey TE, Varshney M, Flint JA, Rajasekaran S, Shah DO, Dennis DM. Treatment of local anesthetic-induced cardiotoxicity using drug scavenging nanoparticles. Nano Lett 2004; 4: 757-9.

28. Lin PL, Huang HH, Fan SZ, Tsai MC, Lin CH, Huang CH. Effect of ropivacaine on endothelium-dependent phenylephrine-induced contraction in guinea pig aorta. Acta Anaesthesiol Scand 2007; 51: 1388-93.

29. Groban L, Deal DD, Vernon JC, James RL, Butterworth J. Does local anesthetic stereoselectivity or structure predict myocardial depression in anesthetized canines? Reg Anesth Pain Med 2002; 27: 460-8.

30. Weinberg GL, Ripper R, Murphy P, Edelman LB, Hoffman W, Strichartz G, et al. Lipid infusion accelerates removal of bupivacaine and recovery from bupivacaine toxicity in the isolated rat heart. Reg Anesth Pain Med 2006; 31: 296-303. 